\title{
A incorporação da racionalidade neoliberal na educação e a organização escolar a partir da cultura empresarial
}

\author{
Marcio Giusti Trevisol ${ }^{1}$ \\ Maria de Lourdes Pinto de Almeida²
}

\section{RESUMO}

O artigo é resultado de uma reflexão sobre a forma com que a racionalidade neoliberal tem colonizado o campo educativo, empregando na educação, seja escolar, seja superior, uma cultura empresarial, completamente voltado ao mercado capitalista. O neoliberalismo existente no perfil do Estado Brasileiro institui uma normatização da vida na sua totalidade, a partir de valores referenciais, que passam a organizar as instituições e a própria subjetividade. Neste sentido, nosso objetivo vai ao encontro de pontuar como a razão de mundo ancorada nos princípios neoliberais coloniza a educação e, sobretudo, a escola, tornando-a uma instituição que se organiza e opera a partir de uma cultura em que a lógica predominante é a empresarial. O problema norteador da discussão fundamenta-se na defesa de que a escola não deve ser tratada como uma empresa, sob pena de produzirmos experiências formativas contrárias aos ideais republicanos de educação. A pesquisa caracteriza-se como exploratória, com abordagem teóricobibliográfica e documental. A escrita investigativa dialoga com os autores Dardot e Laval (2016) e com o documento da Comissão das Comunidades Europeias (1995). Portanto, defende-se que a escola como

1 Mestre em Ética e Filosofia Política pela Universidade Federal de São Carlos. Doutorando em Educação na Universidade de Passo Fundo (UPF). Professor da Universidade do Oeste de Santa Catarina (Unoesc), Líder do grupo de pesquisa "Comunicação, Mídia e Sociedade". Membro e pesquisador do grupo de pesquisa GEPES -UPF (Grupo de Estudos e Pesquisa em Educação Superior). Participa da Rede ibero-americana de estudos e pesquisas em políticas, processos de educação superior - RIEPPES - Unoesc/Unicamp e do Grupo de Estudos e Pesquisas em Políticas de Educação Superior da Região Sul - GEPPES SUL, ambos sediados na PPGEd da Unoesc. Email: marcio.trevisol@unoesc.edu.br.

2 Doutora em Filosofia. História e Educação, pela Unicamp. Pós-doc em Políticas Educacionais pela USP e em Política, Ciência e Tecnologia pela Unicamp. Docente do Programa de Pósgraduação em Educação da Unoesc/SC. Pesquisadora colaboradora do PPGEd URI/ RS. Pesquisadora associada do Giepes Unicamp. Líder do Grupo de Estudos e Pesquisas em Educação Superior Unoesc - Unicamp. Vice-líder do Grupo Internacional de Estudos e Pesquisas em Educação Superior - Geipes Unicamp. Líder da Rede Iberoamericana de Estudos e Pesquisas em Políticas e Processos de Educação Superior - Riesup da FE da Unicamp. Pesquisadora do CNPq e do Obeduc. E-mail: malu@04gmail.com 
espaço educativo deve ser refletida à luz de certos referenciais que não sejam os da racionalidade neoliberal, a qual, baseada nos princípios de concorrência, competividade e eficiência, passa a organizar as escolas, tornando-as empresas e que essa lógica empresarial no espaço escolar corrói experiências formativas democráticas.

Palavras-chave: Racionalidade neoliberal. Escola. Cultura empresarial. Educação.

\section{The incorporation of neoliberal rationality in education and the school organization from corporate culture}

\section{ABSTRACT}

The article is the result of a reflection on the way that neoliberal rationality has colonized the educational field employing in the education, whether schooling or higher, a business culture, completely geared to the capitalist market. The neoliberalism existing in the profile of the Brazilian State, establishes a normalization of life in its totality from reference values that begin to organize institutions and subjectivity itself. In this sense, our objective is to point out the reason of the world anchored in the neoliberal principles colonize the education and, above all, the school, making it an institution that is organized and operates from a culture where the predominant logic is the business. The guiding problem of the discussion is based on the defense that the school should not be treated as a company, otherwise we will produce formative experiences contrary to the republican ideals of education. The research is characterized as exploratory with a theoretical-bibliographic and documentary approach. The research writing, dialogues with the authors Dardot and Laval (2016) and with the document of the Commission of the European Communities (1995). Therefore, neoliberal rationality based on the principles of competition, competitiveness and efficiency starts to organize schools into companies. Business reasoning in school space erodes democratic formative moments For this reason, the school as an educational space must be reflected in the light of certain references that are not of neoliberal rationality.

Keywords: Neo-liberal rationality. School. Business culture. Education. 


\section{La incorporación de la racionalidad neoliberal en la educación y la organización escolar a partir de la cultira empresarial}

\section{RESUMEN}

El artículo es resultado de una reflexión sobre la forma con que la racionalidad neoliberal ha colonizado el campo educativo, empleando en la educación, sea escolar, sea superior, una cultura empresarial, completamente orientada al mercado capitalista. El neoliberalismo existente en el perfil del Estado Brasileño instituye una normalización de la vida en su totalidad a partir de valores referenciales que pasan a organizar las instituciones y la propia subjetividad. En este sentido, nuestro objetivo va al encuentro de puntuar cómo la razón de mundo anclada en los principios neoliberales coloniza la educación y, sobre todo, la escuela, tornándola una institución que se organiza y opera a partir de una cultura en que la lógica predominante es la empresarial. El problema norteador de la discusión se fundamenta en la defensa de que la escuela no debe ser tratada como una empresa, bajo pena de que produciremos experiencias formativas contrarias a los ideales republicanos de educación. La investigación se caracteriza como exploratoria con abordaje teórico-bibliográfico y documental. La escritura investigativa dialoga con los autores Dardot y Laval (2016), y con el documento de la Comisión de las Comunidades Europeas (1995). Por tanto, se defiende que la escuela como espacio educativo debe ser reflejar a la luz de ciertos referenciales que no sean los de la racionalidad neoliberal, la cual basada en los principios de competencia, competitividad y eficiencia pasa a organizar las escuelas, tornándolas empresas y que esa lógica empresarial en el espacio escolar desgasta experiencias formativas democráticas.

Palabras-clave: Racionalidad neoliberal. Escuela. Cultura empresarial. Educación.

\section{Introdução}

Para início de conversa, precisamos situar nosso campo de discussão com relação ao neoliberalismo. A pretensão é compreender e discutir o neoliberalismo como razão-mundo. Essa tese é amplamente defendida por Dardot e Laval (2016), que definem o neoliberalismo como um conjunto de discursos, práticas e dispositivos que determinam um novo modo de governo dos homens sobre o princípio universal da 
concorrência. O fundamento está no entendimento de que o neoliberalismo, antes de ser apenas uma ideologia ou uma política econômica, é primeiramente uma racionalidade, que estrutura tanto instituições públicas e privadas, como a própria subjetividade.

Entender o neoliberalismo a partir do conceito empregado por Dardot e Laval (2016), de razão-mundo, nos permite que seja desenvolvida uma compreensão de como as influências do modelo produtivo capitalista se constituem na educação e, sobretudo, na escola. Não se trata apenas de compreender a influência dos princípios neoliberais a partir de uma lógica externa que se impõe sobre a escola, mas de um processo, aparentemente espontâneo, que se constitui nas relações sociais e na própria escola. Em outras palavras, são discursos práticos admitidos socialmente e que migram para o campo escolar. Então, a educação passa a organizar-se por uma racionalidade neoliberal e as escolas definem seus quadros e currículos a partir de uma cultura empresarial da competividade, inovação e concorrência para o mercado tecnológico e global. Tomando essa questão, a tese que pretendemos defender é a antítese da escola como empresa, ou seja, a escola não pode ser tomada e organizada pela lógica empresarial, sob pena de perdermos um espaço formativo para a democracia. A pesquisa investigativa localiza-se na busca de fundamentar uma resposta à questão: 'Por que a escola não deve se guiar por uma lógica empresarial? Ao responder a esta questão, o trabalho objetiva pontuar como a racionalidade neoliberal se constitui na educação e, em especial, na escola. Deste objetivo, decorrem inquietações como: I) quais as consequências de uma escola pautada pela cultura empresarial para a democracia? II) como a racionalidade neoliberal se traduz em modelos educativos aceitos e legitimados a partir dos atores que compõem o universo educacional? III) por que devemos pensar e estruturar modelos educacionais que façam frente à racionalidade neoliberal? IV) quais as consequências de experiências formativas marcadas pela lógica mercadológica?

Para responder a essas inquietações, o artigo é organizado em três partes: a) na primeira, situamos a questão da racionalidade neoliberal como condição de governabilidade, isto é, como o neoliberalismo passa a ser a nova razão de mundo ao normatizar instituições e as práticas sociais a partir de certos princípios como da concorrência e da competividade. Para favorecer esse discurso, lançaremos um olhar 
sobre a obra 'A nova razão do mundo: ensaios sobre a sociedade neoliberal' dos autores Dardot e Laval (2016); b) na segunda parte, apresentamos, à luz da racionalidade neoliberal, os pressupostos de uma educação para a concorrência e competência presentes no livro branco sobre a educação e formação da Comissão das Comunidades Europeias, 'Ensinar e aprender: Rumo à sociedade cognitiva' (1995). Esta segunda parte estabelece um diálogo com os conceitos e definições apresentados no primeiro momento; c) na terceira parte, abordamos os conceitos que evidenciam a presença da cultura empresarial na escola a partir da obra 'A escola não é uma empresa: o neoliberalismo em ataque ao ensino público' do pesquisador Christian Laval (2004). Nesta etapa do trabalho, defenderemos os motivos que justificam que a escola não deve ser tratada como empresa. A metodologia é teórico-bibliográfica e documental com um diálogo com os autores Dardot e Laval (2016) que se constituem como importantes pesquisadores desta temática.

Portanto, entender o neoliberalismo como racionalidade de mundo nos permite compreender a organização das escolas a partir de uma cultura empresarial. Esta forma de organização escolar possibilita que os processos educativos sejam pensados a partir do princípio da concorrência, competividade e eficiência. Isso gera algumas condições no mínimo questionáveis, a saber: formação de conglomerados educacionais que objetivam somente o lucro (tornando a educação um grande mercado no século XXI), a destruição do processo de aprendizagem em voga de modelos flexíveis, dinâmicos e rápidos, legitimação de discursos que sustentam que a escola deve formar para o mercado de trabalho, perpetuação de uma ideologia técnico-científica. Os pontos tratados são consenso entre pesquisadores da área educacional, sobretudo, para Laval (2004) que apresenta como o neoliberalismo realiza um ataque à escola pública, ao instituir uma racionalidade avessa aos ideais republicamos e democráticos de educação. Segundo Laval (2004, p. 107), a ideologia neoliberal propõe que "a escola deve ter uma lógica mercadológica, ela é convidada a empregar técnicas mercantis para atrair o cliente, deve desenvolver e inovação e esperar "retorno de imagem" ou financeiro, deve se revender e se posicionar no mercado". Sendo assim, a escola transformada em empresa fortalece a racionalidade neoliberal e sufoca as perspectivas de uma formação integral. 


\section{O neoliberalismo como nova razão do mundo e a formação do sujeito empresa}

Para discutir esta tese, utilizaremos os conceitos de Dardot e Laval (2016). A posição assumida pelos autores rompe com os conceitos e posicionamentos que entendem o neoliberalismo apenas como modelo econômico, político ou ideológico. O neoliberalismo não atua apenas na destruição de programas de regulamentação das instituições, mas produz a própria existência, isto é, forma a subjetividade e define como vamos nos comportar e nos relacionar socialmente. $\mathrm{O}$ neoliberalismo define certa norma de vida nas sociedades ocidentais

O conceito de governabilidade empregado por Dardot e Laval (2016) é decorrente dos estudos e pesquisas produzidas por Michel Foucault no livro 'Nascimento da Biopolítica' (2008). Nesta obra, o autor pretende lançar uma análise do liberalismo e do neoliberalismo não como teorias econômicas, mas como práticas de governo de si. A originalidade está no fato de entender o neoliberalismo como racionalidade normativa, que define orientações políticas do Estado e do mercado, mas também atua na normatização da conduta pessoal. De acordo com Foucault (2008), consiste em definir a moldura mais racional no interior da qual os indivíduos se dedicarão a suas atividades consoante com seus planos pessoais. Neste aspecto apresentado, a governabilidade está ligada a uma atividade social e não à institucionalização coercitiva do Estado. Então, a governabilidade é de si mesmo e não do Estado. A aceitação normativa da racionalidade neoliberal como estilo de vida impõe regras e técnicas de convivência sobre si mesmo e sobre os outros. Para Dardot e Laval (2016), governar é conduzir a conduta dos homens, desde que se especifique que essa conduta é tanto aquela que se tem para consigo mesmo quanto aquela que se tem para os outros.

A tomada da noção do neoliberalismo pelo viés político da governabilidade nos permite compreender como os princípios do neoliberalismo são aceitos e legitimados nas instituições e na subjetividade como razão de mundo. Por via de regra, esta compreensão permite: a) entender que os princípios de concorrência e competividade colonizaram a vida social em todas as esferas, tecendo novas formas de ser e comportar-se. Dardot e Laval (2016) pontuam que os próprios Estados, ao adotarem políticas intervencionistas para enfrentar as crises, definem o princípio da concorrência generalizada como forma de superação das 
dificuldades, sejam elas sociais ou financeiras. A cultura empresarial da concorrência e da competividade torna-se o motor social de comportamento para os sujeitos e a base de políticas institucionalizas nos Estados como forma de competir regionalmente e mundialmente; b) em segundo lugar, a via da reflexão política permite compreender que é uma mesma lógica normativa que rege as relações de poder e as maneiras de governar em níveis e domínios muito diferentes da vida econômica, política e social (DARDOT; LAVAL, 2016). O fato é que a normatividade da governabilidade neoliberal está em todos os campos sociais.

O modelo de produção toyotista trouxe uma perspectiva e um discurso de um trabalho mais flexível nos setores de produção, enfatizando o trabalho em equipe, porém, a regulação deste modelo aliado ao local e mercado de trabalho deu-se muito mais a favor do empresário do que dos trabalhadores. No que diz respeito à questão de qualificação, o toyotismo toma como base a sua estrutura de flexibilização dos trabalhadores. O objetivo é transformá-los em profissionais polivalentes, 'trabalhadores multifuncionais'. No taylorismo-fordismo, a preocupação central era destruir o saber do trabalhador pela via de especialização; o método japonês trabalha segundo o princípio da desespecialização, polivalência operária e intensificação do trabalho (CORIAT, 1994). O trabalho é desenvolvido com base no princípio do 'tempo partilhado', isto é, o tempo de trabalho é determinado pela eficácia do trabalhador individual em seu posto de trabalho (ALVES, 2006).

Isso explicaria os motivos de aceitação do neoliberalismo mesmo quando este provoca crises e retrocessos à democracia e às conquistas sociais. Para Dardot e Laval (2016), o dispositivo de eficácia permite a aceitação e legitimação de uma razão baseada na concorrência e competividade que aniquila e corrói qualquer pretensão democrática de coletividade e de espaços comuns. É preciso pensar e implementar estratégias, tipos de educação da mente, de controle do corpo, de organização do trabalho, moradia, descanso e lazer que seriam a forma institucional de novo ideal de humano. $\mathrm{O}$ dispositivo de eficácia apontado por Dardot e Laval (2016) favoreceu a produção de mentes e corpos aptos a funcionar de acordo com a lógica de produção e consumo do mundo capitalista. A nova normatividade das sociedades capitalistas se concretizou na vida cotidiana na fabricação do homem eficaz, útil, dócil ao trabalho e disposto ao consumo. Segundo Dardot e Laval (2016), o princípio de utilidade como discurso homogeneizante, permanente e penetrante em todas as 
esferas sociais está aniquilando a pluralidade do sujeito e conduzindo o sistema educacional para a adoção de lógicas mercantilizadas, que aniquilam as perspectivas de uma formação integral dos alunos. A formatação dos currículos educacionais, atendendo à racionalidade do neoliberalismo, vem atuando na formação do homem-empresa.

\begin{abstract}
A partir de então, diversas técnicas contribuem para a fabricação desse novo sujeito unitário, que chamaremos indiferentemente de "sujeito empresarial", "sujeito neoliberal" ou simplesmente neossujeito. Não estamos mais falando das antigas disciplinas que se destinavam, pela coerção, a adestrar os corpos e a dobrar os espíritos para torná-los mais dóceis - metodologia institucional que se encontrava em crise havia muito tempo. Trata-se agora de governar um ser cuja subjetividade deve estar inteiramente envolvida na atividade que exige que ele cumpra (DARDOT; LAVAL, 2016, p. 327).
\end{abstract}

Os apontamentos dos autores permitem compreender que a formação do homem passa a ser sustentada sob o ideal de um homem ativo, não como propunha o iluminismo ou os Frankfurtianos, mas como um sujeito-empresa que é responsável unicamente pelo seu sucesso ou fracasso.

A racionalidade neoliberal calcada nos valores de concorrência e competividade permite apontar: a) que a escola ao adotar a razão de mundo neoliberal se tornou empresa e assegura a formação de uma geração que adota seus princípios como valores culturais; b) que os atores que compõem a escola_ pais, alunos e professores_ adotam como prática e discurso uma nova relação com o saber (CHARLOT, 2000), isto é, a escola é vista como campo formativo para o sucesso no trabalho; c) que os ideais de uma educação republicana, exposta e desenvolvida por Durkheim no livro 'Educação e Sociologia' (2007) dão lugar a uma educação restrita, enxuta e homogênea, que reprime experiências formativas além daquelas propostas pelo utilitarismo econômico; d) que as experiências formativas na escola não consideram a democracia como valor ao propor uma lógica formativa baseada no individualismo, competividade e concorrência; e) por fim, a escola como empresa torna-se um perigo ao futuro da humanidade. Ao considerar a racionalidade neoliberal como fundamento para a formação do cidadão, colocam-se em ameaça a ética e as conquistas sociais. 


\section{Cultura empresarial e a formação educacional na escola}

Ao adotar o termo cultura empresarial na escola, não pretendemos descrever uma lógica de organização produtiva empresarial, mas apontar como valores tipicamente ligados às empresas passam a ser tomados como cultura. O sentido do emprego de cultura empresarial simboliza um estado de espírito, uma cultura e uma racionalidade que orienta ações pessoais e define objetivos de instituições. O conceito epistemológico básico para sustentar essa tese tomaremos de Dardot e Laval (2016). A governabilidade empresarial está ligada a uma racionalidade de conjunto, que tira força de seu próprio caráter abrangente, já que permite descrever as novas aspirações e as novas condutas dos sujeitos, prescrever os modos de controle e influência sobre si e outros. Da individualidade do sujeito, passando pela empresa e o Estado há um discurso prático socialmente aceito, baseado na lógica da competitividade, da concorrência e do sucesso no mundo capital. A normatização desse discurso precisa fundamentalmente comprometer-se com a formação. Este é o ponto e a pergunta- chave: como a escola contemporânea absorve a racionalidade neoliberal e, portanto, a cultura empresarial na formação dos sujeitos?

A resposta a essa questão começa no entendimento de que a racionalidade neoliberal se sustenta na normatização da vida a partir dos valores de competência, concorrência e sucesso. Desta maneira, a escola como um campo materializado atua na formação do espírito, fornecendo uma estrutura curricular que garante perpetuação e manutenção da racionalidade neoliberal. Essa condição é maior que apenas formar para o mercado de trabalho, pois estamos formando um espírito de um tempo, um novo ethos, uma nova cultura, um estilo de vida.

Neste sentido, o eu-empresa, o sujeito neoliberal ou neossujeito é resultado de um processo formativo que confere essa nova racionalidade. A grande inovação da tecnologia neoliberal é vincular diretamente a maneira como o homem 'é governado' à maneira como ele próprio 'se governa' (DARDOT; LAVAL, 2016). Esse é o ponto, de como o homem, ao absorver os valores neoliberais passa a entender-se como uma empresa. Claro que teríamos muitas considerações a fazer a partir dessa tese, mas nosso objetivo é perceber como o processo formativo da escola favorece a formação do eu-empresa, em outras palavras, como a escola vai tornando-se agente formador para a racionalidade neoliberal 
em seus discursos, na sua organização, nas teorias educacionais e nos documentos.

A agenda política no campo educacional passou a ser profundamente marcada por dois campos: por um lado, a defesa da aproximação da educação com os aspectos de competitividade do mercado e, por outro lado, a defesa de que a educação deve ser o contraponto à lógica mercadológica. O primeiro aspecto ganha legitimidade na medida em que as crises econômicas ameaçam as conquistas sociais e colocam em questionamento as políticas estatais. Neste campo, a defesa de uma escola que se aproxima da empresa ganha força e legitimidade, logo, a escola torna-se um espaço de formação de jovens para a concorrência e a competitividade.

O documento da Comissão das Comunidades Europeias, o Livro Branco sob título'Ensinar e aprender: Rumo à sociedade cognitiva' (1995) retrata como se apresenta um ideal de educação estruturado a partir da racionalidade neoliberal. O documento é uma síntese dos objetivos da União Europeia para enfrentar os desafios da competitividade do mercado global. Já no preâmbulo apresenta o objetivo do documento, a saber, as políticas de formação e aprendizagem, elementos fundamentais para a melhoria do emprego e da competitividade deverão ser reforçados, especialmente a formação continuada (COMISSÃO DAS COMUNIDADES EUROPEIAS, 1995). Para tal, atribuem condição estratégica à educação na formação de sujeitos preparados para o mercado neoliberal.

Neste documento, atribui-se um papel decisivo à educação e à formação, não apenas porque são consideradas as pedras angulares da sociedade cognitiva, mas porque se espera que por meio dos sistemas educativos seja possível uma coesão social em torno do valor da concorrência e competitividade. Essa ideia pode ser observada quando afirma que a educação e a formação cada vez mais serão consideradas como vetores de identificação, integração, promoção social e realização pessoal. O sentido de formação e educação, seja na escola, na empresa ou em qualquer outro local deve assegurar o futuro e a realização do sujeito, o que se dá através da inovação, da empregabilidade e da competitividade.

O livro (1995) apresenta uma síntese da nova linguagem da aprendizagem, que tem dado o ritmo das discussões políticas e as definições da estruturação das escolas. A ideia é favorecer um tipo de formação alicerçado por objetivos de Estado, que enfrente as crises pro- 
vocadas pelo mercado global. Para Afonso e Antunes (2001), isso é um equívoco, uma ideologia e um perigo à sustentabilidade da democracia. Em termos de discurso oficial e de orientações vindas de instâncias como a União Europeia, ao sobrevalorizar-se nomeadamente o pressuposto de que a aprendizagem que conta é aquela que se guia pela maximização da sua utilidade econômica imediata - justificada em termos de uma racionalidade idêntica à da teoria do capital humano -, a ideia da sociedade da aprendizagem é instrumental e redutora, ainda que seja possível, a partir de sua problematização, verificar que poderá cumprir outras funções latentes mais amplas.

A segunda parte do Livro Branco (1995) é denominado 'Construir a sociedade cognitiva' e é composta de cinco objetivos: fomentar a aquisição de novos conhecimentos, aproximar a escola e a empresa, lutar contra a exclusão, dominar três línguas, tratar em pé de igualdade o investimento físico e a formação. Os cinco objetivos expressos no documento evidenciam uma agenda política que tem ganhado corpo e influenciado outros documentos de políticas educacionais. Para (AFONSO; ANTUNES, 2001, p. 91).

Nesta nova agenda, a educação e a formação são evocadas como soluções fundamentais para, por um lado, preparar a mão de obra qualificada que atenda as exigências da competitividade econômica e às mudanças no sistema ocupacional e, por outro lado, para preparar indivíduos que, a partir de uma escolaridade básica bem-sucedida, sejam capazes de continuar a aprender e a incorporar novos conhecimentos que os mantenham menos vulneráveis aos processos de exclusão social.

Partindo dessa condição, é possível pontuar a primeira tese, na qual os valores referenciais de organização da educação a partir da racionalidade neoliberal sufocam outras perspectivas formativas, sobretudo, aquelas vinculadas às humanidades e às artes. A educação formalmente aceita e que deve ser praticada em escolas é a que se dirige pelas demandas do mercado global. A própria noção de uma formação continuada que evite a exclusão social está ligada à perspectiva única de empregabilidade, isto é, o oferecimento de uma educação continuada que produza um capital humano para o mercado, tanto na formação de mão de obra quanto de uma nova racionalidade de mundo. Pois bem, a segunda tese é que esse tipo de educação cumpre com a formação de 
capital humano para o trabalho individualizado e reafirma a ideologia de que o desenvolvimento de um Estado forte se dá pelas vias da inovação e da concorrência econômica como os demais Estados. Isso é percebível em discursos práticos, que afirmam uma escola utilitarista que deve entusiasmar seus alunos para a inovação e a para tecnologia, a fim de que isso eleve o PIB do país.

O segundo objetivo geral do Livro Branco (1995) refirma essas teses ao propor a aproximação da escola com a empresa. Conforme a Comissão das Comunidades Europeias (1995), essa aproximação é uma prioridade que deve contar com a máxima adesão dos parceiros. Para tal, propõe três condições: abertura da educação ao mundo do trabalho; implicação da empresa no esforço de formação, não só dos seus trabaIhadores, mas também dos jovens e dos adultos; a terceira condição, que complementa as duas primeiras, propõe o desenvolvimento da cooperação entre estabelecimentos de ensino e empresas.

A terceira condição é reveladora de um movimento que estabelece a escola como extensão dos ideais empresariais e econômicos. Como definido na Comissão das Comunidades Europeias (1995, p. 41), "[...] o reforço dos laços entre educação e a empresa passa em primeiro lugar pelo desenvolvimento da aprendizagem. É um método de formação adaptado a todos os níveis de qualificação e não só aos mais baixos". A aprendizagem se inicia no ensino superior por inciativa de escolas de comércio ou de engenharias.

Embora nesta passagem o documento dê ênfase ao ensino superior, é importante salientar que processos educativos em escolas de nível primário também se comprometem com esse objetivo. São inúmeros exemplos de parcerias entre escolas e empresas que possuem a intenção de formar jovens ávidos para o mundo competitivo do neoliberalismo. Não se trata de uma postura de resistência radical à área de inovação, mas de pontuar que o crescimento dessas propostas soberanas nas políticas educacionais está conduzindo para um modelo educacional homogêneo, que não privilegia outras experiências formativas.

Neste sentido, a Comissão das Comunidades Europeias (1995) e demais organismos multilaterais, como UNESCO e FMI, estão influenciando as políticas educacionais ao propor que a educação e, sobretudo, a escola tomem a cultura empresarial como princípios e intenção formativa. É preciso formar, à maneira da racionalidade neoliberal, indivíduos competentes e competitivos, que procuram maximizar seu capital hu- 
mano em todos os campos, trabalhando para si para se tornarem mais eficazes. É uma formação alienada, que elimina condições de convívio baseadas na cooperação, solidariedade e fidelidade. Para Sennett (2012), esses laços de coesão social são suprimidos com o novo capitalismo, que introduz, com uma nova racionalidade, princípios que favorecem o individualismo. Por consequência, a nova ordem mundial, baseada nesses princípios, aponta ao declínio do homem público (ou dos espaços públicos). Segundo Dardot e Laval (2016), os novos paradigmas que englobam tanto o mercado de trabalho como o da educação e da formação por toda a vida (long life training) e empregabilidade são modalidades estratégicas significativas.

A escola como ambiente formativo torna-se no mundo globalizado a própria empresa, não somente pela sua organização, mas pela condição de formação da consciência dos indivíduos. A sociedade cognitiva neoliberal, ao propor a formação do eu-empresa produz uma nova ética empresarial que passa a orientar os comportamentos sociais. Conforme Dardot e Laval (2016), a ética empresarial exalta o homem que se faz a si mesmo e a realização plena. Ela transforma o trabalho no veículo privilegiado da realização pessoal: sendo bem-sucedidos profissionalmente, fazemos de nossa vida um sucesso. Os apontamentos dos autores auxiliam na empreitada de defender a tese que a escola no limiar do século XXI se tornou a própria empresa, ao adotar uma cultura empresarial, não apenas na formação de mão de obra, mas na formação ética, cultural e subjetiva de indivíduos que aceitam e reproduzem os valores neoliberais.

Os aspectos relativos à presença da cultura empresarial na escola podem ser observados nas políticas de accountabitily que têm colocado padrões e metas avaliativas. A escola tomada por uma avaliação em larga escala responsabiliza a individualidade e favorece um autocontrole da qualidade. Para Schneider e Nardi (2012), nas últimas décadas, temos assistido, nos países capitalistas ocidentais, à disseminação de políticas de avaliação em larga escala, de prestação de contas e responsabilização sem necessária correspondência entre os pilares que constituem esse sistema. Propaga-se um modelo regulatório de accountability, cujas concepções político-ideológicas sobrepujam os governos nacionais e descaracterizam o sistema como instrumento para a legitimação de um regime democrático substantivo, participativo e crítico. Obviamente não é intenção restringir a uma análise superficial um tema tão complexo. $O$ 
fato é que a adoção em larga escala de certos tipos de avalição corresponde à consolidação da racionalidade neoliberal. Tal movimento constitui a escola em uma empresa que passa a buscar o sucesso na resposta a metas estipuladas. Processos como esses efetivam sistemas de ensino que conferem grande importância ao resultado e desqualificam o processo de ensino, além de comprometer qualquer memória espaço-temporal, pois o que interessa são os resultados momentâneos da avaliação. Sendo assim, os processos de accountability escolar se identificam com os processos de gestão de empresas.

Resta-nos neste momento apontar algumas condições que concorrem para tornar a escola uma empresa: a) o reducionismo das propostas pedagógicas, ao homogeneizar apenas uma educação voltada aos interesses do mercado de trabalho; b) formação através da escola de mentes e espírito que aceitam como normas de comportamento princípios neoliberais de convivência humana; c) redução de áreas de saber como humanidades e artes para dar lugar a componentes 'mais úteis' ao modelo econômico; d) Articulação da escola com a empresa ao reduzir a educação à formação para o emprego; e) produzir um ensino flexível adequado às demandas de mercado. Essas condições serão aprofundadas na próxima seção.

Da antítese: a escola é uma empresa

Nesta terceira seção vamos nos esforçar para responder à questão sugerida no título de nosso artigo: quais as consequências pedagógicas de tomar a cultura empresarial como condição de organização das escolas? Nosso subtítulo, de forma dialética, aponta os motivos pelos quais a escola não deve ser uma empresa e nem adotar uma cultura empresarial.

Em primeiro lugar, a escola não deve ser uma empresa porque isso representa o retorno ao modelo reducionista e antirrepublicano na educação. Para Laval (2004), a escola neoliberal designa certo modelo escolar neoliberal, que considera a educação como um bem essencialmente privado e cujo valor é, antes de tudo, econômico. Não é a sociedade que garante a todos os seus membros o direito à cultura. São os indivíduos que devem capitalizar recursos privados cujo rendimento futuro será garantido pela sociedade. O fato é que um modelo escolar fundado em uma racionalidade neoliberal de capital humano para o mercado 
exclui uma formação diversa e plural, que garanta a convivência social e a democracia. Como pontua Durkheim (2007), a escola não pode ser propriedade de um partido. $\mathrm{O}$ autor chama a atenção para o caráter republicano da escola, isto é, o sistema escolar não pode ser propriedade, monopólio político, ideológico ou econômico. O espaço escolar deve ser por excelência de domínio público e de interesse comum, controlado e definido a partir dos interesses do Estado republicano. Segundo Laval (2004), a escola na concepção republicana devia contrabalançar as tendências dispersivas e anônimas de sociedades ocidentais cada vez mais marcadas pela especialização profissional e a divergência de interesses particulares.

A escola não deve ser uma empresa na medida em que adota uma postura reflexiva com relação à racionalidade neoliberal. Os discursos produzidos por organismos multilaterais, como Comissão das Comunidades Europeias, OCDE, ONC, Banco Mundial e FMl, costumam defender uma aproximação entre escola e empresa (ou mundo produtivo). A adoção de políticas educativas que atendam a esses interesses coloca a escola como uma prestadora de serviços para as demandas de mercado. Neste sentido, a escola torna-se espaço de formação de sujeitos que consideram a competividade e a concorrência como normatização das relações sociais no trabalho e na convivência familiar. Como pontua Biesta (2017, p. 37-38),

[...] o principal problema com a nova linguagem da aprendizagem é que ela tem facilitado uma nova descrição do processo da educação em termos de uma transação econômica, isto é, uma transação em que (1) o aprendente é o (potencial) consumidor, aquele que tem certas "necessidades", em que (2) o professor, o educador ou a instituição educacional são vistos como o provedor, isto é, aquele que existe para satisfazer as necessidades do aprendente, e em que (3) a própria educação se torna uma mercadoria - "uma coisa" - a ser fornecida ou entregue pelo professor ou pela instituição educacional, e a ser consumida pelo aprendente.

Seguindo os apontamentos do autor, a escola torna-se 'neoescola' ou 'escola neoliberal', na medida, que estabelece ritos e formas de ensino e aprendizagem ligadas ao sucesso e eficácia que seus alunos terão no campo de trabalho. Para Biesta (2017), essa lógica existe por trás da defe- 
sa de que as instituições escolares devem ser flexíveis, corresponder aos interesses e necessidades dos alunos/pais e fornecer um ensino de qualidade, eficiente e competitivo, fazendo bom uso do dinheiro investido.

Numa sociedade de mercado, numa lógica de globalização, façamos dos conhecimentos e saberes uma práxis voltada à construção de outro mundo. Portanto, a escola tem um papel fundamental que não é apenas reproduzir conhecimentos estáticos, mas tornar-se espaço de discussão, reflexão e análise do contexto mundial, articulando a escola com os interesses populares. Segundo Saviani (1997, p. 81), “[...] trata-se da apropriação das camadas populares das ferramentas culturais necessárias à luta social que travam diuturnamente para se libertar das condições de exploração em que vivem".

Em terceiro lugar, a escola entendida como empresa se constitui como um espaço que consagra a lógica econômica. Na racionalidade neoliberal, a escola passa à sujeição à razão econômica. Para Laval (2004), o'homem flexível' e o'trabalhador autônomo' constituem, assim, as referências do novo ideal pedagógico, e a competividade econômica é também a competividade do sistema educativo. Neste sentido, a escola torna-se peça central para a formação do eu-empresa. A empresa de si inaugura uma nova ética de valorização do eu. A escola ao adotar a cultura empresarial está formando sujeitos que aderem aos conceitos de competividade e concorrência e os legitimam como uma entidade psicológica e social. Por isso, no campo do emprego não falamos em direitos trabalhistas, mas em pequenas empresas (eu empresa) que presta serviço (isso vai incidir diretamente nas leis trabaIhistas que por ora não vamos tratar). No novo mundo da 'sociedade de desenvolvimento', o indivíduo não deve mais se ver como trabalhador, mas como uma empresa que vende um serviço em um mercado (DARDOT; LAVAL, p. 2016). Do ponto de vista da escola, isso significa fornecer programas de ensino flexíveis e que valorizem o conceito de empreendedorismo.

A linguagem empregada na elaboração das políticas educacionais traz o conceito de empreendedorismo como chave para o sucesso dos alunos no mundo globalizado. As práticas de empreendedorismo são facilmente identificadas nos programas educacionais de escolas públicas e privadas muitas vezes através de convênios entre empresas e a escola. A ideia central da educação para o empreendedorismo está na defesa que cada indivíduo deve aprender a ser um sujeito 'ativo' e 'au- 
tônomo' na e pela ação que ele deve operar sobre si mesmo (DARDOT; LAVAL, 2016). O conceito de autonomia não deve ser confundido com o conceito empregado por Kant (1999) ou pelos frankfurtianos como Adorno (1995). A ideia de um sujeito ativo e autônomo na concepção liberal é decorrente de uma perspectiva empreendedora para o mundo dos negócios e não como capacidade reflexiva das contradições sociais, por isso o esforço observado em documentos como a Comissão das Comunidades Europeias (1995) de defender uma formação por toda a vida. A constante formação, neste caso, é para atender as demandas latentes da empregabilidade (formação de mão de obra especializada). O conceito de autonomia da racionalidade neoliberal na escola traz a aparente ideia de emancipação, mas na prática forma indivíduos ineficientes para a compreensão da totalidade e das contradições produzidas pelo modelo de desenvolvimento neoliberal.

A educação como emancipação é o contraponto ao modelo de escola empresa e a racionalidade neoliberal. Para Adorno (1995), a educação crítica é tendencialmente subversiva. É preciso romper com a educação como mera apropriação de instrumentos técnicos e receituários para a eficiência, instituindo o aprendizado aberto à elaboração da história e ao contato com o outro não-idêntico. A escola como campo de conhecimento dos ideais republicanos não pode tornar-se expressão ideológica da racionalidade neoliberal. O núcleo da experiência formativa reside na capacidade da compreensão do presente como totalidade histórica de contradições e sentidos. A perspectiva de uma educação pautada pela racionalidade neoliberal ameaça qualquer perspectiva de formação cultural como Bildung.

Em quarto lugar, a escola na perspectiva empresarial adota padrões de gestão que se caracterizam pela concorrência, eficiência e competividade. A gestão da escola passa a ser regida pelos ideais empresariais de eficácia que gradativamente são medidos por critérios quantitativos (como provas, testes de desempenho, meritocracia...). Para Laval (2004), no plano da administração escolar, a tendência é para a descentralização, para o gerenciamento moderno e para a 'gestão da empresa'. Neste sentido, duas condições passam a vigorar; a) a gerência de custo-gastos com a educação passa a ser medida pelos benefícios diretos e imediatos da empregabilidade, 'chamado custo-aluno'; b) a escola tomada pela cultura empresarial adere às condições econômicas e passa a obedecer às restrições do mercado. 
O pesquisador Charlot (2000 apud LAVAL, 2004) explica adequadamente esse fenômeno com a expressão Estado regulador. Para o autor, o Estado neoliberal tem a tendência de delegar aos escalões inferiores os serviços descentralizados, a ação cotidiana, racionalizada segundo as regras do gerenciamento dito 'participativo'. Esse Estado guiado pelos novos princípios da ação pública fica conhecido por definir as grandes perceptivas e avaliar, a posteriori, os resultados de uma gestão mais autônoma, com a ajuda de um sistema estatístico rigoroso, que deve permitir o controle das escolas e da educação. O fator que verifica o sucesso e a eficiência da escola são as respostas dadas aos critérios estipulados pelo Estado. Então, um ensino eficiente e competente é medido pelo fator custo-aluno, isto é, o critério econômico torna-se central para a definição das políticas educacionais, semelhantes às tomadas por empresas pelo 'custo-benefício'. Não raro é possível presenciar essas falas em políticos, embora não seja objeto deste estudo analisar conteúdo dessas falas.

Em quinto lugar, a escola como ambiente formativo deve se opor à racionalidade neoliberal e propor um discurso antagônico aos modelos flexíveis de educação propostos pelos organismos multilaterais como o documento da Comissão das Comunidades Europeias (1995). A escola no século XXI é organizada não apenas para a formação de mão de obra, mas atua na formação de mentes que internalizam como condição indispensável para a vida a concorrência e a competividade. Não estamos falando apenas na relação formação-emprego, mas em algo mais complexo, que tem relação direta com o modo como o sujeito se comporta socialmente. A formação de mentes que legitimam como norma social a competividade e a concorrência permite que aceitem de forma natural as crises sociais do modelo neoliberal porque já perderam de vista a capacidade crítica e analítica de conjuntura. A escola como empresa adota os princípios e valores de mercado ao vender (marketing) a imagem de uma instituição que atua na preparação e formação de jovens para o sucesso. A condição, portanto, é que uma escola deve formar para o sucesso profissional e em decorrência contribuir para o desenvolvimento do país. Para Nussbaum (2015), muitas políticas educacionais se baseiam no paradigma de que a educação deve promover o desenvolvimento nacional entendido como crescimento econômico. No entanto, a tese de uma educação voltada somente para a inovação, tecnologia e competividade não significa melhoria nas condições de 
vida, em especial, nas áreas da saúde, segurança, distribuição de renda, redução da pobreza e da miséria.

No contexto do mundo do trabalho, podemos afirmar que a principal característica capitalista é a força de produção ter assumido a forma de mercadoria e o trabalhador produzir para o capital e não para si, sendo mais um simples objeto de produção. Desse modo, o conhecimento é na contemporaneidade também uma mercadoria da qual o'capital' necessita para sua continuidade. Se até bem pouco tempo a mão de obra era uma importante mercadoria, no mundo globalizado a força de trabalho perde valor e abre-se uma nova categoria chamada sociedade do conhecimento, que nada mais é que a nova mercadoria do capital. Importante se faz ressaltar que a informação e a inovação são dois fundamentos essenciais, segundo Ferreira (2003a), da sociedade mundializada, em que a circulação maciça de capitais se baseia na informação, na comunicação e no saber.

Essa questão nos traz pelo menos algumas evidências que nos ajudam a entender quando a escola se torna empresa. A primeira evidência é o enxugamento e a flexibilidade dos currículos educacionais para atender ao sucesso no mundo corporativo. Esta postura, gradativamente, leva à diminuição das humanidades e das artes. Como já apontado por Nussbaum (2015), a valorização de áreas com finalidade econômica e a desvalorização de outras áreas formativas levará a uma crise de valores, especialmente, os democráticos. Antes de tudo, uma educação para o crescimento econômico despreza essas áreas da educação da criança porque elas não parecem conduzir ao progresso pessoal ou ao progresso nacional. A segunda evidência é a relação que pais e alunos possuem com a escola. A busca pela formação fica restrita aos ideais de sucesso e a escola torna-se uma prestadora de serviços. A relação com o saber, como descreve Charlot (2000), que deveria ser de uma formação integral, fica restrita ao reducionismo de uma formação para o sucesso no mundo dos negócios. Essa, na maior parte das vezes, é a justificativa dos pais para enviar seus filhos para a escola. A terceira evidência que é a dificuldade de formarmos para uma compreensão totalizante da sociedade e para uma postura ética. A pergunta central é: como em um sistema educativo que formamos para o sucesso através da concorrência e competividade vamos conceber o outro em um sentido de alteridade? A escola não é uma empresa e não deve tomar a racionalidade de mundo neoliberal como base, sob pena de levarmos a uma crise civilizatória e 
sufocarmos os princípios de coesão social que estão no reconhecimento do outro.

Portanto, a escola como espaço formativo deve atuar com autonomia e uma capacidade crítica e analítica que escape ao determinismo da racionalidade neoliberal. Para isso deve comprometer-se com: a) uma educação crítica e emancipatória; b) o favorecimento de experiências formativas alternativas à lógica utilitarista do mercado; c)a consolidação de programas e currículos baseados em uma educação para a cidadania; d) o fortalecimento de laços de coesão social que estão para além dos princípios de concorrência e competividade; e) a consolidação da democracia entendida como um valor moral.

\section{Considerações Finais}

O neoliberalismo como nova razão de mundo normatiza a vida na sociedade em todas as esferas a partir do princípio da concorrência e da competividade. $O$ fato de que a linguagem neoliberal, presente em documentos multilaterais como na Comissão das Comunidades Europeias (1995) produz um sentido de aproximação da escola com os interesses e interesses de mercado. Essa lógica é observada nos ideais de formação de jovens para o mercado de trabalho e para a busca do sucesso. Para tanto, poderíamos dizer que não é inexplicável que determinados termos circulem atualmente ao redor dos discursos: management, qualidade total, escola inteligente, impacto, benefício, reengenharia, normas ISO, avaliação em larga escala, dentre outros. Uma dificuldade deste discurso esteve vinculada à questão disciplinar, com um enfoque disciplinar neoliberal, uma epistemologia neoliberal. Para Casassus (2000), um problema que acontece na América Latina tem a ver com a ausência da dimensão educacional.

Nesse contexto, a questão é como a educação poderá ter um papel decisivo como política pública para novos processos de gestão escolar organicamente articuladas com novos processos sociais, voltados à humanização, ética e novos paradigmas de convivência humana?

A condição contemporânea, na qual se estrutura um projeto globalizado baseado no discurso hegemônico da supervalorização da competividade, da concorrência e da eficiência do modelo produtivo de capital é potencialmente degenerativo quando aplicado ao campo educacional. A sua homogeneidade limita e sufoca o surgimento do contraditório, do não-idêntico. $\mathrm{O}$ Estado, como ente jurídico, político e 
ideológico absorve a lógica e define padrões educacionais ligados aos interesses hegemônicos de classe do grande capital internacional.

O projeto hegemônico do grande capital se concretiza na medida em que forma sujeitos que aceitam subjetivamente as normatividades desse sistema. Para Laval (2004), as evoluções econômicas conduziram, ao mesmo tempo, a um progresso cultural e social. O capitalismo globalizado e flexibilizado lança uma retórica atraente e generosa ao se definir como 'libertador'. No campo educacional, assegura as parcerias entre Estados e grupos econômicos que veem no ensino duas grandes possibilidades: a) garantir o mercado promissor e lucrativo; b) atuar de forma deliberada no campo do conhecimento como agentes formativos de sujeitos para compor a ordem mundial produtiva.

Neste sentido, concordando com Laval (2004), a escola está passando de uma instituição para uma organização. A materialidade dessa perspectiva em andamento é verificada nos discursos de modernização das políticas públicas, apresentada como alternativa de modelos educativos eficientes e competitivos. O imperativo de produtividade se impõe a partir do momento que a escola começou a ser concebida como uma organização produtora de serviços úteis e mensuráveis em termos de 'valor agregado' de 'competências' e, em última instância, de preço sobre o mercado de trabalho.

A escola do século XXI, ao absorver a racionalidade neoliberal, torna-se empresa e produz jovens que unificam os ideais neoliberais. Sua normatização ameaça conquistas sociais, não favorecendo uma sociedade democrática. Para Laval (2004), a perda do sentido da escola e do saber na sociedade do capital globalizado não é mais do que um aspecto da crise política, cultural e moral da sociedade capitalista, na qual a lógica predominante traz em si mesma a destruição do vínculo social, em geral, e do vínculo educativo, em particular. A escola não é uma empresa, por isso, sua condição de funcionalidade vai além da ideia utilitarista do mercado.

\section{Referências}

ADORNO, T. W. Educação e Emancipação. São Paulo: Paz e Terra, 1995

AFONSO, Almerindo Janela; ANTUNES, Fátima. Educação, cidadania e competividade: questões em tono de uma nova agenda. Revista Cadernos de Pesquisa, n.113, p. 83-112, junho 2001. 
ALVES, Ana Elizabeth Santos. Qualificação e Trabalho no Capitalismo. Revista da FAEEBA: Educação e Contemporaneidade, Salvador, v. 15, n. 26, p. 45-56, jul./dez., 2006.

BIESTA, Gert. Para além da aprendizagem: educação democrática para um futuro humano. 1.ed. Belo Horizonte: Autêntica, 2017.

CASASSUS, Juan. Problemas de la gestión educativa en América Latina. Chile: UNESCO, 2000.

CHARLOT, Bernard. Da relação com o saber: elementos para uma teoria. Porto Alegre: Artes Médicas Sul, 2000.

COMISSÃO DAS COMUNIDADES EUROPEIAS. Ensinar e aprender: Rumo à sociedade cognitiva. Livro branco sobre a educação e formação. Bruxelas: CCE, 1995

CORIAT.Pensar pelo avesso: o modelo japonês de trabalho e organização. Tradução de Emerson S. da Silva. Rio de Janeiro: Revan; UFRJ, 1994

DARDOT, Pierre; LAVAL, Christian. A nova razão do mundo: ensaios sobre a sociedade neoliberal. 1.ed. São Paulo: Boitempo, 2016.

DURKHEIM, Émile. Educação e sociologia. São Paulo: Edições 70, 2007. FERREIRA, Naura Syria Carapeto (Org.). Formação Continuada e Gestão da Educação. São Paulo: Cortez, 2003.

FOUCAULT, Michel. Nascimento da biopolítica. São Paulo: Martins Fonte, 2008.

KANT, Emmanuel. Sobre a pedagogia. 2. ed. Piracicaba: Editora Unimep, 1999.

LAVAL, Christian. A escola não é uma empresa: o neo-liberalismo em ataque ao ensino público. Londrina: Editora Planta, 2004.

NUSSBAUM, Martha. Sem fins lucrativos: por que a democracia precisa das humanidades. São Paulo: Martins Fontes, 2015.

SAVIANI. Dermeval. Escola e Democracia. 31. ed. São Paulo: Autores Associados, 1997

SCHNEIDER, Marilda; NARDI, Elton Luiz. Políticas de accountability na educação básica e as implicações no trabalho docente. Santiago/ Chile, 2012. Disponível em: http://indicadoresdequalidade.unoesc.edu. br/images/uploads/trab._docente.pdf. Acesso em: 17 jun. 2018. 
SENNETT, Richard. A corrosão do caráter: o desaparecimento das virtudes com o novo capitalismo. 1. ed. Rio de Janeiro: Bestbolso, 2012.

Recebido: abril/ 2019

Aceito: julho/2019 